\title{
SELECTED RISK FACTORS OF DIABETES MELLITUS AMONG ROAD TRANSPORT DRIVERS
}

\author{
ANDRZEJ MARCINKIEWICZ ${ }^{1}$ and DOROTA SZOSLAND ${ }^{2}$ \\ ${ }^{1}$ Nofer Institute of Occupational Medicine, Łódź, Poland \\ Department of Environmental Epidemiology \\ ${ }^{2}$ Nofer Institute of Occupational Medicine, Łódź, Poland \\ The National Centre for Workplace Health Promotion
}

\begin{abstract}
Objectives: Road transport drivers are one of the professional groups whose activities have a strong impact on public safety. In view of the nature of their professional activity, the drivers are at a higher risk of obesity and hypertension, and thus, indirectly, of carbohydrate metabolism disorders such as diabetes mellitus. Materials and methods: Medical documentation was a source of data for the reported study. It derived from medical examinations of truck and bus drivers applying for the new category II driving licence or for prolongation of the one they already had. Results: Excessive body weight was recorded in $62.6 \%$ of the study population; $45.3 \%$ had overweight and $17.4 \%$ were diagnosed with obesity. Hypertension was noted in the medical records of $36.7 \%$ drivers. The prevalence of abnormal BP values was increasing with age. Overweight was found to be a risk factor for hypertension. Hyperglycaemia was found in $47.5 \%$ of the drivers and was also increasing with age. Conclusion: In road transport drivers, the high prevalence of excessive body weight and elevated arterial blood pressure as the risk factors for diabetes indicates a need to undertake multidimensional actions targeted on this particular profession and involving various health care sectors. Prophylactic and detailed pre-placement examinations should be considered, depending on the rate and intensity of the disorders diagnosed. This should be coupled with an introduction of primary and secondary prophylactic activities and monitoring of relevant treatment. A close collaboration with the patient's GP is necessary.
\end{abstract}

Key words:

Diabetes mellitus, Risk factors, Road drivers

\section{INTRODUCTION}

Road transport drivers are among the professional groups whose activities have a strong impact on public safety. Passenger transport operations and truck driving are closely associated with the responsibility for other people's lives. Therefore, following the European Community laws as well as the legal codes of particular Member States, more restricted health status requirements have been defined for truck and bus drivers (group II) [1,2]. In view of the nature of their professional activity, which involves exposure to stress, a sitting working mode, and a shift and night work, the drivers are at a higher risk of obesity and hypertension, and thus, indirectly, of carbohydrate metabolism disorders, such as diabetes mellitus [3]. These diseases may on the one hand increase the risk for traffic accidents, while on the other, they are the reason for long-term sickleaves from work, or even a partial or permanent disability for work, thus contributing to a considerable economic burden [4]. Taking into account the literature reports concerning the high incidence rates of obesity, hypertension and carbohydrate metabolism disorders among drivers, the authors of the present study intended to investigate these risk factors specifically among road transport drivers. In Poland, road transport drivers undergo regular medical examinations, defined by occupational health regulations. Therefore, the authors gained access to and

Title of the project: IMP 2.2/2007 "Carbohydrate metabolism disturbances among public transport drivers — a design of model management procedure for drivers with hyperglycaemic status" (Nofer Institute of Occupational Medicine in Lódź).

Received: April 28, 2010. Accepted: June 2, 2010.

Address reprint request to A. Marcinkiewicz, Nofer Department of Environmental Epidemiology Institute of Occupational Medicine, 91-348 Łódź, św. Teresy 8 (e-mail: am@imp.lodz.pl). 
reviewed respective medical documentation in order to assess the prevalence of the risk factors for diabetes in that particular profession

\section{MATERIALS AND METHODS}

The project was a cross-sectional study covering road transport drivers (buses and trucks above $3.5 \mathrm{t}$ ) examined over the period of 2001-2007 at an outpatient clinic of occupational medicine in a Polish town with ca. 350000 inhabitants.

The medical documentation that was a source of data for the reported study derived from medical examinations of truck and bus drivers applying for the new category II driving licence or for prolongation of the licence they already had. The documentation was uniform and conformed to the Regulation of the Minister of Health, of September 15, 1997, defining the types of medical documentation required in occupational health examinations, and the procedures for its development, processing, circulation and storage [5].

\section{RESULTS}

In the study population, the youngest driver examined was 19 years of age, while the oldest one was 68 . The mean age of the population was 39 years. The largest group were the drivers 30-34 years of age (15.9\%), and more than 56\% represented the age group of 25-44 years.

Excessive body weight (BMI: $>25 \mathrm{~kg} / \mathrm{m}^{2}$ ) was recorded in 357 drivers, which makes up $62.6 \%$ of the study population; 258 subjects $(45.3 \%)$ had overweight (BMI: $\left.25-29.9 \mathrm{~kg} / \mathrm{m}^{2}\right)$ and 99 subjects $(17.4 \%)$ were diagnosed with obesity (BMI: $>30 \mathrm{~kg} / \mathrm{m}^{2}$ ).

BMI analysis in particular age groups revealed that the highest number of drivers with obesity could be found among those above 60 years of age (50\%). Overweight referred to $60 \%$ of the drivers from the age group 55-59 years, while obesity to $25 \%$ and normal body weight to as little as $16 \%$ of drivers in this age group.

Hypertension ( $\geq 140 / 90 \mathrm{mmHg}$ ) was noted in the medical records of $209(36.7 \%)$ drivers. The prevalence of abnormal BP values was increasing with age; hypertension was found in $19 \%$ of drivers under 25 years of age, in $44 \%$ of drivers in the age group $45-49$ years, $61 \%$ in the age group 55-59 years and in 78\% among drivers above 60 years of age.

According to medical records, hypertension was diagnosed in 28 (4.9\%) subjects. Positive correlation with age was observed: no cases among subjects under 30 years of age, less than 3\% in the age group 30-45 years and then as much as $52 \%$ in the group $45-49$ years, $12 \%$ in the group $50-54$ years, $13.7 \%$ in the group $55-59$ years - and $35.7 \%$ in the subjects above 60 years of age.

In general, overweight was found to be a risk factor for developing hypertension; of the 357 subjects with overweight, 171 (47.9\%) had concomitant hypertension. For comparison, in the group of 213 subjects with normal body weight, only 38 (17.8\%) had arterial blood pressure values slightly exceeding the upper normal limits.

The above relationship was also confirmed when the study group was limited to the subjects with documented hypertension. In this group, hypertension was found in two subjects $(0.9 \%)$ with normal body weight and in 26 overweight subjects $(7.3 \%)$.

Odds ratio calculations revealed that the risk for hypertension in overweight subjects was 4.23-fold as high as in those with normal body weight (95\% CI: 2.82-6.36).

Hyperglycaemia was found in 271 drivers (47.5\%). In 102 subjects (17.89\%), blood glucose level ranged between 5.5 and $5.79 \mathrm{mmol} / \mathrm{l}$, and in 87 subjects $(15.26 \%)$, between 5.8 and $6.1 \mathrm{mmol} / \mathrm{l}$. It should be noted that 20 subjects (3.5\%) presented with fasting glucose levels $\geq 7 \mathrm{mmol} / \mathrm{l}$, which was a diagnostic criterion of diabetes mellitus.

The incidence of carbohydrate metabolism disorders increased with age. In the age groups above 40 years, hyperglycaemia was more frequent than normoglycaemia. The highest prevalence rate was found in the eldest group - hyperglycaemia was identified in 11 (78.57\%) out of 14 drivers above 60 years of age.

The calculated risk factor for hyperglycaemia, expressed by the odds ratio of 2.91, confirms the higher risk for hyperglycaemia in the subjects above 45 years vs. the younger age groups (95\% CI: 2.03-4.17) 
In previous fasting glucose test records, hyperglycaemia was found in $54 \%$ of overweight subjects vs. $36.6 \%$ of subjects with normal body weight.

The calculated OR of 2.03 indicated that the higher risk for hyperglycaemia referred to overweight subjects vs. the group of subjects with normal body weight (95\% CI: 1.44-2.88).

An increased prevalence of hyperglycaemia in the subjects with excessive body weight could also be observed in the analysis of fasting glucose concentration in relation to BMI. While elevated fasting glucose levels were found in $24 \%$ of underweight subjects and $38 \%$ of subjects with normal body weight (BMI: $18.5-24.9 \mathrm{~kg} / \mathrm{m}^{2}$ ), the test results revealed hyperglycaemia in $50 \%$ of overweight subjects (BMI: $25-29.9 \mathrm{~kg} / \mathrm{m}^{2}$ ) and in $62 \%$ of subjects with obesity (BMI: $>30 \mathrm{~kg} / \mathrm{m}^{2}$ ).

With regard to arterial BP measurements performed during the prophylactic examinations, $61.7 \%$ of hypertensive patients were also diagnosed with hyperglycaemia. In the group of normotensive patients, hyperglycaemia was found in $39.3 \%$ of subjects.

If one takes into consideration the detailed criteria of hypertension, the relationship between hyperglycaemia and hypertension is even more evident. While hyperglycaemia was found in merely $40 \%$ of normotensive subjects, its prevalence rate increased to $60.3 \%$ (111 cases) in the group of 184 subjects with hypertension (based on a single BP measurement at the last prophylactic examination). An even higher rate of hyperglycaemia (71.4\%) was observed in subjects with previously diagnosed hypertension. In the analysis of particular risk factors, the odds ratio was 2.48, indicating a higher risk for hyperglycaemia among hypertensive vs. normotensive subjects (95\% CI: $1.75-3.53$ ).
The analysis concerned also the prevalence of carbohydrate metabolism disorders in overweight and/or hypertensive subjects. Among 171 drivers who had both overweight and hypertension, hyperglycaemia was noted in 112 subjects, which makes up $65.5 \%$ of this group. For comparison, in the group of subjects in whom no such risk factors for diabetes were found, the prevalence of hyperglycaemia was $34.8 \%$.

The presence of one risk factor for diabetes, either excessive body weight or hypertension, was found in 224 subjects (39.3\% of the study population). Hyperglycaemia was noted in 99 subjects $(44.2 \%)$.

The concurrence of two risk factors for diabetes, namely excessive body weight and hypertension, was observed in 171 subjects, 112 (65.5\%) of whom had hyperglycaemia. OR calculation indicated a 3.54-fold higher risk for hyperglycaemia incidence in the subjects with two risk factors for diabetes, namely excessive body weight and hypertension (95\% CI: 2.28-5.52).

Moreover, the prevalence of hyperglycaemia was found to be dependent on the degree of obesity, particularly when combined with hypertension. In the group of subjects with abnormal arterial BP, hyperglycaemia occurred in 17 of 35 subjects with normal body weight (48.6\% of that subgroup), in 66 (59.5\%) of 111 subjects with overweight, and in 46 of 60 subjects with obesity, which made up $76.7 \%$ of the subgroup with hypertension and BMI $>30 \mathrm{~kg} / \mathrm{m}^{2}$. However, this tendency was not so clear among the subjects with normal arterial BP. In that group, hyperglycaemia was noted in $35.7 \%$ of all the 157 subjects with normal BMI, $44.2 \%$ of all the 147 overweight subjects and $43.2 \%$ of all obese subjects (with normal arterial BP in each category).

Table 1. Prevalence of hyperglycaemia in the study population, by combination of particular risk factors

\begin{tabular}{lcccccc}
\hline \multirow{2}{*}{\multicolumn{1}{c}{ Risk factors for diabetes mellitus }} & \multicolumn{2}{c}{ Hyperglycaemia } & \multicolumn{2}{c}{ Normoglycaemia } & \multicolumn{2}{c}{ Total } \\
\cline { 2 - 7 } \multicolumn{1}{c}{} & $\mathrm{n}$ & $\%$ & $\mathrm{n}$ & $\%$ & $\mathrm{n}$ & $\%$ \\
\hline Only hypertension & 129 & 61.7 & 80 & 38.3 & 209 & 100 \\
Only excessive body weight & 194 & 54.3 & 163 & 45.7 & 357 & 100 \\
Either hypertension or excessive body weight & 99 & 44.2 & 125 & 55.8 & 224 & 100 \\
Hypertension and excessive body weight & 112 & 65.5 & 59 & 34.5 & 171 & 100 \\
No risk factors & 61 & 34.8 & 114 & 65.1 & 175 & 100 \\
\hline
\end{tabular}




\section{DISCUSSION}

The prevalence of excessive body weight (BMI: $>25 \mathrm{~kg} / \mathrm{m}^{2}$ ) that was noted in the present study (62\% of the study population) was $10 \%$ higher than the excessive body weight estimate of $58 \%$ for the male population in Poland in the age group of 18-94 years (NATPOL PLUS study) [6]. Overweight was found in $45.3 \%$ of the subjects and obesity in $17.4 \%$. In a comparable group of male subjects in the NATPOL PLUS study, overweight and obesity was noted in $39 \%$ and $19 \%$, respectively [6], and in the WOBASZ study, in $41.6 \%$ and $21.2 \%$, respectively [7].

Although the incidence of excessive body weight increased with age, like in the general population [6-8], the study population showed a higher prevalence of excessive body weight in the younger age groups: as much as $40 \%$ of the drivers aged 20-34 years had overweight (compared to $31.3-33.9 \%$ of same age subjects in the POL-MONICA BIS study) and obesity was identified in $11.73 \%$ of young drivers (4.7-4.8\% in POL-MONICA BIS) [8].

The higher prevalence of carbohydrate metabolism disorders observed among persons with excessive body weight that is reported in literature was also confirmed in the present study. The risk of hyperglycaemia among the subjects with excessive body weight was more than twice as high (2.03) as in those with normal body weight. This value was slightly higher than that obtained in the SCREENPOL study, where respective OR for carbohydrate metabolism disorders in overweight males was 1.7 [9], However, it was lower than the risk for hyperglycaemia calculated in the POL-MONICA BIS study (OR: 2.42 for overweight and 4.4 for obesity, respectively) [8].

Hypertension ( $\geq 140 / 90 \mathrm{mmHg}$ ) was another risk factor for diabetes; the condition concerned $36.67 \%$ of the subjects. It should, however, be noted that the above value was the result of a single measurement of arterial blood pressure and the diagnosis of hypertension may be disputable. Moreover, the medical records contained no information about any additional BP measurements or of the mode of calculating the average results of such measurements. According to the criteria adopted by the Polish Association for Hypertension, arterial blood pressure should be measured during two consecutive visits, or twice during the same visit, and only the mean value of the two measurements should be considered informative [10].

A similar remark refers also to the "Polish Project of 400 Towns", in which the prevalence of arterial blood pressure $>140 / 90 \mathrm{mmHg}$ measured on the first screening visit was $65.8 \%$ in all the male subjects, while elevated arterial blood pressure values were confirmed in $76.1 \%$ of those subjects [11].

The prevalence of hypertension among drivers would be lower if only those cases were considered which had been registered in the medical records of prophylactic examinations and had been based on data from medical history, final diagnosis or reports on therapy. In our study, hypertension confirmed by such documentation was identified in only $5 \%$ of the subjects. However, the calculated morbidity rate for hypertension seems to be much lower than the actual levels, as it does not account for the new cases identified during routine, periodic examinations, as well as for the subjects who either consciously or unconsciously did not take any treatment despite persistent symptoms or abnormal measurement results.

The evidence for this hypothesis derives from other studies in which the prevalence of hypertension in Polish men above 20 years of age is estimated to be at a much higher level, approximating 42\% [6]. One should also bear in mind that the individual awareness of hypertension varies from $49 \%$ [12] to $67 \%$ [6].

In the study population, the incidence of abnormal blood pressurevalues increased with age. However, in comparison with the findings of the NATPOL PLUS study, there was a higher proportion of subjects with $\mathrm{BP}>140 / 80 \mathrm{mmHg}$ in the younger age groups. Elevated BP was more than three times as frequent among drivers $\leq 25$ years of age (18.8\%) as in the NATPOL PLUS study (5\%) and more than twice as in the age group $31-44$ years (32.3\% vs. $15 \%$ in NATPOL PLUS), while less frequent in the age group 45-64 years (52.33\% vs. $45 \%$ in NATPOL PLUS [6]).

The four-fold higher risk of elevated BP in the subjects with excessive vs. normal body weight is consistent with literature data that obesity is a factor predisposing to hypertension [13]. According to the findings of Polish studies, 
the prevalence of overweight and obesity in hypertensive subjects is estimated to be $68 \%$ [14], while the respective value is $72.6 \%$ in Sweden [15] and 77\% in Greece [16]. In the present study, this rate was much higher, amounting to $81 \%$ of subjects with a single BP measurement above $140 / 80 \mathrm{mmHg}$ and as much as $93 \%$ of subjects diagnosed with hypertension.

When analysing the effects of hypertension on carbohydrate metabolism, the authors found that elevated BP values were significantly more frequent among hyperglycaemic subjects $(61.72 \%)$ than those with normal blood glucose levels (38.28\%). This finding is consistent with the results obtained by Ruprecht [17] who demonstrated a higher prevalence of hypertension in similar groups (68.6\% vs. $48 \%$ ) and with the study by Bandurska-Stankiewicz [12] where the prevalence of hypertension was even higher $(85.36 \%$ and $57.93 \%$, respectively). However, in both the studies, the obtained values may have been associated with an older age of the study population $(58.5 \pm 12.45$ years and $58 \pm 9.5$ years, respectively), which is an additional risk factor both for hypertension and hyperglycaemia.

In the present study, a more than 2.5 -fold higher risk for developing hyperglycaemia was noted in the subjects with elevated arterial BP than in normotensive subjects. This value is higher than in the SCREEN-POL study, where the risk of carbohydrate metabolism disorders was 1.7 times higher [9].

According to literature data, a greater number of the risk factors for diabetes makes its development more probable $[18,19]$. Such a relationship was also observed in the present study: the concurrence of two of the risk factors for diabetes, namely excessive body weight and hypertension, increased the risk of hyperglycaemia more than 3.5 times.

It should then be concluded that in road transport drivers, excessive body weight and elevated arterial blood pressure are the risk factors for diabetes. The high prevalence of these conditions as well as of the hyperglycaemia alone indicates a need to undertake multidimensional actions targeted on this particular profession and involving various health care sectors.

First of all, this refers to the occupational medicine services which are directly engaged in activities for workers health protection due to their exposure to occupational hazards or strenuous working conditions. More attention should be paid to providing better health care to elder drivers, especially those with excessive body weight or elevated blood pressure. More frequent prophylactic and detailed pre-placement examinations should be considered, depending on the rate and intensity of the disorders diagnosed. This should be coupled with an introduction of primary and secondary prevention activities, including proper diet, physical activity and relevant treatment. A close collaboration with the patient's GP is necessary.

GPs should have some knowledge on the profession of their patients and in the case of professions associated with public safety, monitor the patients health condition, providing current data to occupational medicine services and arranging prophylactic activities. A good clinical practice at this level of health care should include systematic contacts with occupational medicine services and an exchange of data, especially in the case of any changes in the patients health which require intensive treatment and may increase the risk of a traffic accident.

\section{ACKNOWLEDGEMENTS}

The study was performed at the Nofer Institute of Occupational Medicine in Łódź under project IMP 2.2/2007 "Carbohydrate metabolism disturbances among public transport drivers a design of model management procedure for drivers with hyperglycaemic status".

\section{REFERENCES}

1. Commission Directive 2009/112/EC of 25 August 2009 amending Council Directive 91/439/EEC on driving licences. Off J Eur Union 2009;52(L 223):26.

2. Diabetes and Driving in Europe. A Report of the Second European Working Group on Diabetes and Driving, an advisory board to the Driving Licence Committee of the European Union [cited 2010 January 27]. Available from: URL: http:// ec.europa.eu/transport/road_safety/behavior/doc/diabetes_ and_driving_in_europe_final_1_en.pdf. 
3. Zimmet P, Alberti KGMM, Shaw J. Global and societal implications of the diabetes epidemic. Nature 2001;414:782-87.

4. Schmitt-Koopmann I, Schwenkglenks M, Spinas GA, Szucs TD. Direct medical costs of type 2 diabetes and its complications in Switzerland. Eur J Public Health 2004;14:3-9.

5. Regulation of the Minister of Health and Social Welfare, of 15 September 1997, on the types of medical documentation used in occupational health services and the producers for its development and and storage. Law Gazette Sep 15, 1997;120:768, with amendments specified in Law Gazette Jan 16, 2003;37:328 [in Polish].

6. Podolec P, Karch I, Pająk A, Kopeć G, Broda G, Drygas W, et al. Epidemiology and prevention. Kardiol Pol 2006;64: 1031-7 [in Polish].

7. Biela U, Pająk A, Kaczmarczyk-Chałas K. Prevalence of excessive body weight and obesity in women and men aged 20-74. WOBASZ Multicentre Study. Kardiol Pol 2005;63 (6 Suppl 4):632-5 [in Polish].

8. Pupek-Musialik D, Kujawska-Łuczak M, Bogdański P. Obesity and overweight - epidemy of the 21st century. Przew Lek 2008;1:117-23 [in Polish].

9. Sieradzki J, Wilkins A, Szczepański M. SCREEN-POL 2 active screening and early detection of type 2 diabetes in general practice in Poland. Results of multicentre, national screening survey. Diabet Prakt 2005;6(3):103-14 [in Polish].

10. Symonides B, Lewandowski J. Approach to hypertension 2008. Recommendations of the Polish Society of Hypertension and College of Family Physicians. Przew Lek 2008;6:14-20 [in Polish].

11. Wierucki Ł, Zdrojewski T, Mogilnaya I, Zarzeczna-Baran M, Wizner B, Mędraś M, et al. The Polish 400 Towns
Project - results of the pilot survey. Nadcis Tetn 2004;8(5): 301-17 [in Polish].

12. Bandurska-Stankiewicz E, Myszka-Podgórska K, Cylkowska B, Surdykowski L, Moczulska B. Incidence of unknown diabetes and prediabetes in population of Warmia and Mazury Region. Przegl Kardiodiabetol 2007;2(1):41-47 [in Polish].

13. Poirier P, Giles TD, Bray G, Hong Y, Stern JS, Pi-Sunyer FX, et al. AHA Scientific Statement. Obesity and Cardiovascular Disease: Pathophysiology, Evaluation, and Effect of Weight Loss. Circulation 2006;113:903-4.

14. Krupa-Wojciechowska B, Semetkowska-Jurkiewicz E, Zdrojewski T. Hypertension in patients with obesity, diabetes mellitus and hyperlipidaemia. Przew Lek 2004;7(1):20-31 [in Polish].

15. Jonsson S, Hedblad B, Engstrom G, Nilsson P, Berglund G, Janzon L. Influence of obesity on cardiovascular risk. Twenty three-year follow-up of 22025 men from an urban Swedish population. Int J Obes 2002;26:1046-53.

16. Kotsis V, Stabouli S, Bouldin M, Low A, Toumanidis S, Zakopoulos N. Impact of obesity on 24-hour ambulatory blood pressure and hypertension. Hypertension 2005;45:604.

17. Ruprecht Z, Kamińska A, Skibicka M, Junik R. The incidence of impaired carbohydrate metabolism in the examined group of subjects with risk factors. Diabet Prakt 2006;7(6):374-81 [in Polish].

18. Lawrence JM, Bennett P, Young A, Robinson AM. Screening for diabetes in general practice: cross-sectional population study. BMJ 2001;323:548-51.

19. Oberlinner Ch, Neumann SM, Ott MG, Zober A. Screening for pre-diabetes and diabetes in the workplace. Occup Med (Lond) 2008;58(1):41-5. 